\title{
Health Status Perception of People Close to Retirement Age: Relationship with Mental Health and Healthy Habits
}

Diana Monge-Martín ( $\nabla$ d.monge@ufv.es )

Faculty of Medicine, Universidad Francisco de Vitoria, Madrid

Fernando Caballero-Martínez

Faculty of Medicine, Universidad Francisco de Vitoria, Madrid

Maria João Forjaz

Instituto de Salud Carlos III

Manuel J. Castillo

Faculty of Medicine, Universidad de Granada, Granada

Carmen Rodríguez-Blázquez

Instituto de Salud Carlos III

\section{Research Article}

Keywords: Ageing, health, healthy habits, retirement, depression

Posted Date: June 25th, 2021

DOl: https://doi.org/10.21203/rs.3.rs-646382/v1

License: (9) This work is licensed under a Creative Commons Attribution 4.0 International License. Read Full License 
1 Health status perception of people close to retirement age: Relationship

\section{with mental health and healthy habits}

3

4

5 Short title: Pre- and post-retirement health status perception

6

7

8

9 Diana Monge-Martín ${ }^{1 *}$, Fernando Caballero-Martínez ${ }^{1}$, Maria João Forjaz ${ }^{2.3}$, Manuel J. Castillo4,

Carmen Rodríguez-Blázquez².5.

11

12

${ }^{1}$ Faculty of Medicine, Universidad Francisco de Vitoria, Madrid. 'Instituto de Salud Carlos III,

National Center of Epidemiology, Madrid. ${ }^{3}$ REDISSEC. ${ }^{4}$ Faculty of Medicine, Universidad de

Granada, Granada. ${ }^{5}$ CIBERNED

15

16

17

*Corresponding Author:

Name: Diana Monge-Martin

19

Address: Universidad Francisco de Vitoria

20

Carretera Pozuelo a Majadahonda, km 1,800 - 28223 Madrid

21

e-mail: d.monge@ufv.es

22

Phone: 917091400

23

24

25 


\section{Abstract}

2

3 Background: The ageing of today's society intensifies the need for the correct and healthy ageing of the elderly, in order to ensure their overall well-being. Practical strategies are needed to acquire healthy habits at this stage of life. The aim of this study is to analyse the life habits of subjects close to retirement age and the factors that could influence these habits (gender, physical and mental health).

Methods: A national (Spain) observational, descriptive and cross-sectional study, in which people close to retirement age are surveyed. The online survey included matters regarding sociodemographic, family, work, leisure, social participation and health indicators.

Results: The study comprised of 1,700 participants (581 working; 714 retired), average age $=63$ years (DT 5.7); 52\% women. Most reported having a satisfactory social life (90\%), living in pairs (74\%), not smoking (80\%), following a Mediterranean diet (73\%) and taking medicines daily (70\%). Disability (WHODAS-12) was higher in men (8.2 vs 6.5, $\mathrm{p}<0.001)$ although women showed more health problems and depression (mild-severe) $(27 \%$ vs $17 \%, p<0.001)$, with a healthier diet and lower physical/work activity. The multivariate model showed a significant association of health status (EQ-VAS) with disability level, number of chronic diseases, sleep habits, exercise, diet, and alcohol consumption. When the level of depression was introduced, age and being a woman were also found to be related. In the subgroup of those retired or working $(n=1295)$, retirees reported a better health status, associated with less disability, fewer chronic illnesses, lower depression, good eating and sleeping habits, and exercise.

Conclusions: The results show that retirement does not necessarily mean worse health, but rather an opportunity in life to reinforce favourable health activities and correct those lifestyle factors that deteriorate it. This, together with the differences observed according to gender in the perception of clinical and psychological health, will allow for the design of strategies that promote healthy ageing. 


\section{BACKGROUND}

2 The ageing of today's society, as a result of the low fertility rate and the continued fall in the adult

3 mortality rate, is unprecedented in human history [1]. On a global scale, the growth rate in the number of people over 60 is twice that of the growth rate of the general population [2]. In Spain, more than one fifth of its population is over 60 , with the life expectancy of this group exceeding 80 [3]. Addressing and adapting to this new demographic reality requires substantial changes in political, economic, social and health paradigms [4].

Sooner or later, ageing is associated with a decrease in one's physical and mental capacity, as well as an increased risk of chronic-degenerative diseases and comorbidities [5-7]. Without doubt, ageing also represents a success of human progress, provided that it is accompanied by actions promoting healthy and active ageing that promotes functional capacity, social contribution and quality of life in old age $[5,8]$. Adopting healthy living habits during adulthood and old age can be a protective factor against disease (physical and mental), disability and premature death [9, 10]. Moreover, such a lifestyle helps ensure healthy ageing as defined by the World Health Organization: the process of developing and maintaining the functional capacity that allows wellbeing in old age [11].

Retirement is a critical stage of life that entails the making of crucial decisions regarding health and healthy habits [12]. It may represent an opportunity to adopt healthier routines and living habits; but it may also give rise to the continuance or even intensification of previously established unhealthy behaviours [13]. For this reason, more studies are needed to analyse the determinants and factors associated with healthy living habits at this vital time of life.

Psychological and emotional status may prove to be of great importance at this stage of life. Lifechanging events such as inactivity due to retirement, the increased frequency of chronic diseases, the assumption of new family and social roles (being grandparents), the loss of loved ones or the feeling of being close to death can influence one's psychological state and require both a physical and emotional adaptation [14]. When such adjustment is favourable, in the final stage of life more emotional control and psychological maturity are perceived, with a moderation of positive affect compared to younger people (the young and middle-aged) [15]. In this sense, the acquisition of 
healthy habits such as the continued exercise of certain abilities can positively influence this process of growing maturity [14]. In Spain, more research is needed on the relationships between retirement, life habits, physical health and psychological health. Such information would allow for the design of useful programs and strategies for the promotion of healthy lifestyles, with the ensuing individual and social benefits they suppose.

For this reason, the present study was carried out with the aim of analysing life habits in a population close to retirement age, as well as their relation to physical and mental health, taking into account how gender may also be of relevance in this regard.

\section{METHODS}

\section{Study design and population}

A descriptive, observational and cross-sectional study on a national level, approved by the research ethics committee of the Universidad Francisco de Vitoria (Madrid).

The sample was obtained geographically by means of proportional multistage stratified sampling. The sample size was 1,700 individuals, taken from a target population of 10,506,015 people aged between 55 and 75 years of age (+/- 10 years relative to the average retirement age in Spain) in 2020. In order to participate, after being informed of the purposes of the study, their informed consent was obtained.

The data were collected through a structured and online survey of around 20 minutes, including questions regarding socio-demographic, family, work, leisure, social participation, and health indicators. The survey was conducted by professional interviewers specifically trained for the project. The survey participants constituted a sample similar to the Spanish population in terms of age, gender and geographical distribution. As a prerequisite, all participants needed access to the Internet and had to be familiar with its use, being accustomed to answering online surveys.

For analysis, the variables were grouped as follows: Control variables: socio-demographic characteristics (sex, age, marital status, educational level, employment status), physical health (comorbidity, disability through WHODAS-12[16], number of medications taken per day, self- 
medication) and social and leisure characteristics (social activity, family relationships, sexual life). Independent variables: living habits (sleep, physical activity, tobacco and alcohol consumption, body mass index and preventive behaviours), evaluated by means of ad hoc questions. Mediating variable: mental health (Patient Health Questionnaire, $P H Q-9$ o to 27 point scale $[0=n o$ depression, 1-4=minimal depression, 5-9=mild depression, 10-14=moderate depression, 1519=moderate/severe depression, and 20-27=severe depression] [17-19], the EQ-VAS health perception scale (analogue visual scale of 0 to 100 points) From the EQ-5D-5L questionnaire [20, 21] and the "Five signs of emotional suffering tool " scale [22], which contains questions regarding personality changes, agitated mood, isolation, poor self-care, or hopelessness behaviours, with a dichotomous response option [yes/no]. This questionnaire was answered both by the subject and a proxy (assessment by a family member or caregiver).

\section{Statistical analysis}

A general description of the total study sample $(n=1700)$, by sex, was made, followed by an analysis of the sample of active workers compared to those retired $(n=1295)$. Socio-demographic, family, academic, social and leisure variables as well as health indicators by gender and work status (active, unemployed, family and home care, pensioner and retiree) were compared, using the chi-squared test for categorical variables. Moreover, analysis of variance (ANOVA) was performed for quantitative variables such as age, number of chronic pathologies, PHQ-9, or perceived health status (EQ-VAS) reported by participants. Non-parametric equivalent tests were used when the variables did not follow a normal distribution. Bonferroni correction was used for multiple peer comparisons.

A multivariate linear regression model was performed with self-perceived health status (EQ-VAS) as a dependent variable. The socio-demographic variables, disability level, comorbidities, life habits, depression level, and health indicators were considered as independent variables. Two independent regression models were created - first with the entire sample and subsequently for the group of active workers and retirees. Tests were conducted to ensure that the basic assumptions of linearity, normality, and independence of the multiple linear regression model were met. 
The minimum level of significance was set at $p<0.05$ and version 20 of the IBM SPSS for Windows statistical package was used.

3

4

5

6 7

\section{RESULTS}

\section{Characteristics of respondents}

Total sample

Data were obtained from 1,700 participants, of whom $581(34.2 \%)$ were active workers and 714 (42\%) retired. Table 1 reflects the socio-demographic characteristics and life habits of the total sample by gender, including data on chronic diseases and medication. The mean age of the sample is 63 years old (DT 5.7 years), with $34 \%$ still working. The level of education is mainly at a secondary school $(50 \%)$ or university $(42 \%)$ level of studies. The majority $(90 \%)$ report having a satisfactory or quiet social life, living in a couple (74\%), not smoking (80\%); They report following a Mediterranean diet (73\%), carrying out physical activity more than three days a week $(52 \%)$, almost $70 \%$ of the sample consume medicines daily and almost $50 \%$ consume more than three medicines a day.

\section{Gender}

The sample includes a similar and comparable number of women and men. The percentage of women living with a partner is significantly lower than that of men ( $67 \%$ vs $82 \%)$. There is a high level of participants who report having university studies, $42 \%$, the percentage being slightly lower in men than in women (38 vs $46 \%, p<0.001$ ). In contrast, the percentage of women who report only having received primary education is significantly higher (9.4 vs $5.2 \%)$. The percentage of working women is lower than that of men (30.4 vs. 38.2\%). However, the percentage of women who consider themselves family and home carers is much higher (13.9 vs. $0.7 \%, p<0.001)$. In general, the percentage of women who report having health problems is higher than that of men. There are also differences in certain health habits such as physical exercise, which is practised more by men ( $18 \%$ low physical activity in men versus $25 \%$ in women, $p=0.02$ ) and the perception of sex life $(p<0.001)$, or following a healthy diet, which is more common in women $(p=0.003)$ (table 1). 
1

\section{Perception of clinical and mental health}

2 No significant gender differences were observed in the average health status reported by 3 participants using an analogue quality of life (EQ-VAS) scale (Table 2). The worst state of health 4 was reported by pensioners and the best by the unemployed ( 71.5 vs. $79.6 ; p<0.001$ ), who reported a level of health comparable to those working, with no differences found between men and women (Table 2). Regarding the disability scale measured by the WHODAS-12, men reported a higher value than women ( 8.2 vs $6.5, p<0,001)$, slightly higher being the percentage of women who reported depression (mild to severe) compared to men (27 vs $17 \%, p<0,001$ ).

When analysing health habits with the multivariate model, a strong association was found between the subject's health status and disability level, the number of chronic diseases, sleeping habits, exercise, diet and alcohol consumption (Table 3). Health status was also significantly associated with sleeping well, exercising three or more times a week, drinking some wine or beer at mealtimes and following a Mediterranean diet with fruit and vegetables, legumes and lean meats on a regular basis (Table 3). When analysing the level of depression among subjects, the percentage of variance the model found rose from $33.3 \%$ to $36.3 \%$, with age and sex appearing as new variables associated with the perception of health status (Table 3).

\section{Active workers and the retired}

Table 4 reflects the characteristics of the subsample of active workers and those retired $(n=1295)$. Compared with those working $(3 \% ; n=17)$, a higher percentage of retirees were widowers $(7.2 \%$; $\mathrm{n}=51$ ) and declared themselves to be consuming five or more medications on a daily basis $(p<0.001)$. The degree of depression was lower in retirees $(p=0.001)$. Data on the self-perceived levels of clinical and psychological health of workers and those retired are reflected in Table 5. Overall, retirees showed better overall health and lower levels of depression than those working.

\section{Linear regression model}

Table 6 reflects the results of the linear regression models of perceived health status (EQ-VAS), according to employment status. In the subgroup of those in active employment, the best perceived health status was associated with being a woman, having a lower degree of disability, 
1 a lower number of chronic diseases, a lower degree of depression, and exercising three or more

2 times a week (explained variance 33.9\%). In the subgroup of those retired, the best perceived

3 health status was associated with lower disability, fewer chronic diseases and lower degree of depression, a healthy diet (Mediterranean diet), the consumption of fruit and vegetables, legumes and lean meats on a regular basis, drinking some wine or beer at mealtimes, sleeping well and exercising 3 or more times a week (explained variance $35.9 \%$ ).

\section{DISCUSSION}

8 The present study provides data on the socio-demographic and clinical profile of a countrywide sample of the adult and elderly population, in a time of life close to or recently after (between 55 and 75 years) the average retirement age. It also provides information on factors that influence perceived health status.

Of the 1,700 respondents, the proportion of women and men was very similar, despite the fact that women are the majority population group in the elderly, and even more so the older the age [23]. As the sample was made up of those that volunteered to take part in a computer survey, it may have meant the over-representation of men and women with higher levels of studies, as they require access to and familiarity with the use of the Internet and new technologies. However, despite this observation, the sample may be considered an accurate representation of the national population.

With regard to the employment status, significant gender differences were observed: the percentage of active or retired was higher in men compared to women. In contrast, there was found a higher percentage of women engaged in domestic work, unemployed or pensioners when compared to men. These results are consistent with official data published in Spain and in the European countries (EU-28) by the National Institute of Statistics [3], reflecting the representativeness of the sample.

The self-perceived health status was higher than recently described in Spain by Janssen et al. for the age group 55-64-year-olds [24]. This may be due, in part, to the fact that these data [24] came from a study published by König et al., in 2009 [25], when the economic and social situation in 
1 with the self-perceived state of health at that time. In any case, the effect of certain selection bias related to the origin of the sample population and its particularities with respect to the general Spanish population of the same age group cannot be ruled out.

Perceived health status was associated with lower disability and fewer chronic diseases, sleeping well, increased weekly exercise, and healthy eating (Mediterranean diet) including a moderate drinking of wine or beer during meals. Similar associations have been found in other studies, where perceived health was found to be strongly associated with physical and functional health, among others [26].

The slightly higher value of perceived health status in men is in accordance with previous studies which find a worse self-perception of health in women [24]. In Spain, this worse perception among women has been explained, among other reasons, by having less leisure time [27] and a greater burden of care. However, in our sample, it is women who reported having a significantly better social life. In this sense, a study in the Spanish population showed an increase in social life in women, although it was not statistically significant [1]. Other possible causes for this better perception in men could be greater physical activity $[28,29]$ - in our population, men were slightly more active than women - to which we must also include the absence, in men, of problems associated with menopause, which include osteoporosis and neurovegetative symptoms (hot flashes, sweating, headaches, etc.) $[30,31]$. The presence of these disorders associated with menopause, along with other frequent age-specific comorbidities (including gynaecological cancers) that affect sexual satisfaction [30] may explain why women reported a worse sexual life than men.

In accordance with other studies that reflect a higher consumption of vegetables and fish in women and a higher consumption of processed and red meat in men [32], our results find a significantly healthier diet in women. These results suggest a need to design health promotion programs selectively aimed at improving men's eating habits, particularly training in the basic culinary skills for those who live alone or prepare their own food.

Regarding the perceived level of health according to the working status, as is the case in the general population, both in workers and in those retired, the best health status was associated 
with a lower degree of disability. fewer chronic diseases and exercise three or more times a week. In workers, this perception of having a good diet was also related with being a woman and being retired. In both workers and those retired, the average level of disability was very low, with less disability observed in retirees, although without statistically significant differences. This may be due to the increase in weekly physical activity and to healthier eating habits (Mediterranean diet) reported by retirees, as it could serve as a counterbalance to the deterioration that ageing supposes. Similarly, the many positive effects of habitual moderate exercise are well known [3335], among which a preservation of the cardiac function stands out [6]. In addition, it has been observed that a better diet, such as the Mediterranean diet, has protective effects in elderly individuals, whether or not they suffer from chronic diseases [36].

Those retired reported a significantly higher average number of chronic diseases than active workers, mainly involving osteoarticular, vision, and hypertension problems. This is something to be expected, given the association of ageing with the gradual deterioration of the body, changes in organs and systems [37] and a greater burden of chronic diseases [38], including hearing loss and vision problems $[39,40]$.

With ageing, biological changes occur in the human body affecting mood, physical condition and social activity that influence one's perception of health [41]. In Spain, depression takes ninth place in terms of chronic diseases and is also more prevalent in women $[3,42]$. This phenomenon is reflected in our study: although the percentage of moderate to severe depression is low (less than 1 in 10 participants), it is higher in women. In this sense, it has been noted that, in time, women are more likely than men to suffer from non-lethal disabling conditions such as depression [26, 43]. When depression was included in our analysis, the model showed women and being younger were associated with a better perception of one's health status. It is logical that those women who do not suffer from this type of illness have a better perception of their health status. [26, 43].

In both workers and those retired, a better health status was associated with a lower degree of depression, with a significantly lower degree of depression observed in the latter group. There exist conflicting data on the prevalence of depression in retirement. Despite being related to the loss of employment and the social life associated with work, retirement is also seen as an escape 
1 from work, which is a source of daily stress, obligations and responsibilities. [44, 45] In our case,

2 the most plausible explanation is that of a sense of freedom from work, as our retired population

3 had significantly more satisfactory social life and exercised more.

4 The fact that the sample analysed is composed of people who volunteer to conduct computer surveys (panelists), implies a limitation of the study as it suggests a bias in the representativeness of the overall population. Other limitations to consider are the cross-sectional design of the study, which does not allow the analysis of causality, and that the mental health analysed is selfreferenced and therefore not quantifiable as in the case of cognitive scales.

9 Conclusions: The results of this study show that retirement does not necessarily have a detrimental effect on the health status of this population. Compared to workers, retirees have a lower degree of depression, increased activity, enjoy a healthier diet and have a better perception of their social life, although they do report a worse sexual life. The study clearly reflects how retirement can prove to be a vital opportunity to reinforce favourable health actions and to correct unhealthy behaviours at the end of one's active working life.

The study provides new and valuable information on the determinants of perceived health in the adult and mature stages of life, highlighting the similarities and differences between workers and those retired. Both before and after retirement, the best perceived health status is associated with a lower degree of disability and depression, a lower number of chronic diseases, and with those who exercise three or more times a week. In workers, it was also associated with being a woman and in those who have retired and have a healthy diet and adequate sleep.

Perceived differences according to gender also need to be taken into account. The perception of clinical and psychological health status proved to be similar among men and women, albeit with more depression reported by women. Disregarding depression, being a woman and of a younger age are also associated with a better perception of health status. Men do more physical exercise than women, although women have a healthier diet. The social life of women is better, although they profess to having a worse sex life.

It is important to act upon all identified factors in order to help improve health status and achieve satisfactory ageing. To achieve this, the implementation of specific strategies for each group is 
1 recommended: Preventive, therapeutic and advisory that would promote change in unhealthy

2 lifestyles.

3 Abbreviations

4 12-WHODAS: 12-item version of the World Health Organization Disability Assessment Schedule

5 PHQ: Patient Health Questionnaire

6 VAS: Visual Analogue Scale

7

8 DECLARATIONS

\section{$9 \quad$ Ethics approval and consent to participate}

10 The patients gave informed written consent to be included in the study.

11 Consent for publication

12 Not applicable

13 Availability of data and materials

14 The data that support the findings of this study are available on request from the corresponding

15 author.

16 Competing interests

17 Diana Monge Martín, Fernando Caballero Martínez, Maria João-Forjaz, Manuel J. Castillo and

18 Carmen Rodríguez-Blázquez declare that they have no conflict of interest. Competing interest

19 not declared.

20 Funding

21 The study received a financial support financed by Direct line Aseguradora S.A.

22 Authors' contributions

23 All authors contributed to the study concept and design. Material preparation, data collection and

24 analysis were performed by Carmen Rodríguez-Blázquez, Diana Monge Martín, Maria João-

25 Forjaz and Fernando Caballero Martínez. Manuel J. Castillo made substantial contributions to

26 data interpretation. The first draft of the manuscript was written by Diana Monge Martín and

27 Carmen Rodríguez-Blázquez, with all authors commenting on and making recommendations 
regarding subsequent versions of the manuscript. All authors read and approved the final manuscript.

\section{Acknowledgments}

The study was carried out in collaboration with VIVAZ, the health insurance brand of direct line Aseguradora S.A.

\section{REFERENCES}

1. Pino L, Gonzalez-Velez AE, Prieto-Flores ME, Ayala A, Fernandez-Mayoralas G, RojoPerez F, Martinez-Martin P, Forjaz MJ: Self-perceived health and quality of life by activity status in community-dwelling older adults. Geriatr Gerontol Int 2014, 14(2):464-473.

2. Nations U: World Population Ageing. In. Edited by Affairs DoEaS. New York; 2009.

3. INE. In. https://www.ine.es/: Instituto Nacional de Estadística; 2020.

4. Souza MAHd, Porto EF, Souza ELd, Silva KId: Profile of lifestyle of older elderly persons. Revista Brasileira de Geriatria e Gerontologia 2016, 19:819-826.

5. Han LKM, Verhoeven JE, Tyrka AR, Penninx B, Wolkowitz OM, Månsson KNT, Lindqvist $D$, Boks MP, Révész D, Mellon SH et al: Accelerating research on biological aging and mental health: Current challenges and future directions. Psychoneuroendocrinology 2019, 106:293-311.

6. Jakovljevic DG: Physical activity and cardiovascular aging: Physiological and molecular insights. Experimental gerontology 2018, 109:67-74.

7. Roca F, Lang PO, Chassagne P: Chronic neurological disorders and related comorbidities: Role of age-associated physiological changes. Handbook of clinical neurology 2019, 167:105-122.

8. WHO: Ageing: Healthy ageing and functional ability. In. https://www.who.int/ageing/healthy-ageing/en/; 2020.

9. King DE, Xiang J: Retirement and Healthy Lifestyle: A National Health and Nutrition Examination Survey (NHANES) Data Report. Journal of the American Board of Family Medicine : JABFM 2017, 30(2):213-219.

10. McDonald S, O'Brien N, White M, Sniehotta FF: Changes in physical activity during the retirement transition: a theory-based, qualitative interview study. Int J Behav Nutr Phys Act 2015, 12:25.

11. OMS: Informe Mundial sobre el envejecimiento y la salud. In. https://www.who.int/ageing/publications/world-report-2015/es/: WHO; 2015.

12. Ali-Kovero K, Pietilainen O, Mauramo E, Jappinen S, Rahkonen O, Lallukka T, Kanerva $\mathrm{N}$ : Changes in fruit, vegetable and fish consumption after statutory retirement: a prospective cohort study. The British journal of nutrition 2020:1-6.

13. Zantinge EM, van den Berg M, Smit HA, Picavet HS: Retirement and a healthy lifestyle: opportunity or pitfall? A narrative review of the literature. European journal of public health 2014, 24(3):433-439.

14. Izquierdo Martínez A: PSICOLOGÍA DEL DESARROLLO DE LA EDAD ADULTA: TEORÍAS Y CONTEXTOS. International Journal of Developmental and Educational Psychology 2007, 1(2):67-86. 
15. Marquez-Gonzalez M, Izal Fernandez de Troconiz M, Montorio Cerrato I, Losada Baltar A: [Emotional experience and regulation across the adult lifespan: comparative analysis in three age groups]. Psicothema 2008, 20(4):616-622.

16. Whodas 2.0 12 Items Interview_spanish [https://es.scribd.com/document/129861831/Whodas-2-0-12-Items-Interviewspanish]

17. Diez-Quevedo C, Rangil T, Sanchez-Planell L, Kroenke K, Spitzer RL: Validation and utility of the patient health questionnaire in diagnosing mental disorders in 1003 general hospital Spanish inpatients. Psychosom Med 2001, 63(4):679-686.

18. Kroenke K, Spitzer RL, Williams JB: The PHQ-9: validity of a brief depression severity measure. Journal of general internal medicine 2001, 16(9):606-613.

19. Oncology Nursing Society. Patient Health Questionnaire (PHQ-9) [https://www.ons.org/sites/default/files/PatientHealthQuestionnaire9 Spanish.pdf]

20. Ramos-Goni JM, Craig BM, Oppe M, Ramallo-Farina Y, Pinto-Prades JL, Luo N, RiveroArias O: Handling Data Quality Issues to Estimate the Spanish EQ-5D-5L Value Set Using a Hybrid Interval Regression Approach. Value Health 2018, 21(5):596-604.

21. Cabasés JM: [The EQ-5D as a measure of health outcomes]. Gaceta sanitaria 2015, 29(6):401-403.

22. The Campaign to Change Direction. Five signs of emotional suffering tool [https://www.changedirection.org/]

23. Pérez Díaz J, Abellán García A, Aceitunoo Nieto $P$, Ramiro Fariñas D: Un perfil de las personas mayores en España, 2020. Indicadores estadísticos básicos. Madrid, Informes Envejecimiento en red no 25, 39p. . In. Edited by (CCHS). CSdICCCdCHyS. Madrid; 2020.

24. Janssen MF, Szende A, Cabases J, Ramos-Goñi JM, Vilagut G, König HH: Population norms for the EQ-5D-3L: a cross-country analysis of population surveys for 20 countries. Eur J Health Econ 2019, 20(2):205-216.

25. Konig HH, Bernert S, Angermeyer MC, Matschinger $\mathrm{H}$, Martinez $\mathrm{M}$, Vilagut $\mathrm{G}$, Haro JM, de Girolamo G, de Graaf R, Kovess V et al: Comparison of population health status in six european countries: results of a representative survey using the EQ-5D questionnaire. Med Care 2009, 47(2):255-261.

26. Pino-Dominguez L, Navarro-Gil P, Gonzalez-Velez AE, Prieto-Flores ME, Ayala A, RojoPerez F, Fernandez-Mayoralas G, Martinez-Martin P, Forjaz MJ: Self-perceived health status, gender, and work status. J Women Aging 2016, 28(5):386-394.

27. Adjei NK, Brand T, Zeeb H: Gender inequality in self-reported health among the elderly in contemporary welfare countries: A cross-country analysis of time use activities, socioeconomic positions and family characteristics. PloS one 2017, 12(9):e0184676.

28. Rosenfeld CS: Sex-dependent differences in voluntary physical activity. Journal of neuroscience research 2017, 95(1-2):279-290.

29. Yli-Piipari S, Leskinen E, Jaakkola T, Liukkonen J: Predictive role of physical education motivation: the developmental trajectories of physical activity during grades 7-9. Res Q Exerc Sport 2012, 83(4):560-569.

30. Thomas HN, Neal-Perry GS, Hess R: Female Sexual Function at Midlife and Beyond. Obstetrics and gynecology clinics of North America 2018, 45(4):709-722.

31. Thornton K, Chervenak J, Neal-Perry G: Menopause and Sexuality. Endocrinol Metab Clin North Am 2015, 44(3):649-661.

32. Jurado-Fasoli L, Amaro-Gahete FJ, De-la OA, Martinez-Tellez B, Ruiz JR, Gutierrez A, Castillo MJ: Adherence to the Mediterranean diet, dietary factors, and S-Klotho 
plasma levels in sedentary middle-aged adults. Experimental gerontology 2019, 119:25-32.

33. Hita-Contreras F, Martinez-Amat A, Cruz-Diaz D, Perez-Lopez FR: Osteosarcopenic obesity and fall prevention strategies. Maturitas 2015, 80(2):126-132.

34. Wewege $M$, van den Berg $R$, Ward RE, Keech $A$ : The effects of high-intensity interval training vs. moderate-intensity continuous training on body composition in overweight and obese adults: a systematic review and meta-analysis. Obes Rev 2017, 18(6):635-646.

35. Amaro-Gahete FJ, De-la OA, Jurado-Fasoli L, Ruiz JR, Castillo MJ, Gutierrez A: Effects of different exercise training programs on body composition: A randomized control trial. Scand J Med Sci Sports 2019, 29(7):968-979.

36. Di Daniele N, Noce A, Vidiri MF, Moriconi E, Marrone G, Annicchiarico-Petruzzelli M, D'Urso G, Tesauro M, Rovella V, De Lorenzo A: Impact of Mediterranean diet on metabolic syndrome, cancer and longevity. Oncotarget 2017, 8(5):8947-8979.

37. Samuel $D$, Rowe $P$, Hood V, Nicol A: The relationships between muscle strength, biomechanical functional moments and health-related quality of life in non-elite older adults. Age and ageing 2012, 41(2):224-230.

38. Atella V, Piano Mortari A, Kopinska J, Belotti F, Lapi F, Cricelli C, Fontana L: Trends in age-related disease burden and healthcare utilization. Aging Cell 2019, 18(1):e12861e12861.

39. Jura M, Kozak LP: Obesity and related consequences to ageing. Age (Dordrecht, Netherlands) 2016, 38(1):23.

40. Roth TN: Aging of the auditory system. Handbook of clinical neurology 2015, 129:357373.

41. Dziechciaż M, Filip R: Biological psychological and social determinants of old age: biopsycho-social aspects of human aging. Annals of agricultural and environmental medicine : AAEM 2014, 21(4):835-838.

42. Lahera G, Andrade-González N, Gasull V, Pagés-Lluyot JR, Roca M: [The public perception of depression in Spain]. Anales del sistema sanitario de Navarra 2019, 42(1):31-39.

43. Crimmins EM, Kim JK, Sole-Auro A: Gender differences in health: results from SHARE, ELSA and HRS. European journal of public health 2011, 21(1):81-91.

44. Fehr R: Is retirement always stressful? The potential impact of creativity. Am Psychol 2012, 67(1):76-77.

45. van den Bogaard $L$, Henkens $K$ : When is quitting an escape? How different job demands affect physical and mental health outcomes of retirement. European journal of public health 2018, 28(5):815-819. 
1 Table 1. Socio-demographic characteristics and lifestyle habits of the sample in

2 general and by gender

\begin{tabular}{|c|c|c|c|c|}
\hline $\mathrm{N}=1700$ & General & Male & Female & $p^{* *}$ \\
\hline Gender, \% & - & 48 & 52 & \\
\hline \multicolumn{5}{|l|}{ Population age (years), average } \\
\hline \multicolumn{5}{|l|}{ \pm SD } \\
\hline Marital status, $\%$ & & & & $<0.001$ \\
\hline Married - in a couple & 74.4 & 82.4 & 67 & \\
\hline Single - separated - divorced & 19.1 & 14.6 & 23.3 & \\
\hline Widowed & 6.5 & 3.1 & 9.7 & \\
\hline Educational level, \% & & & & $<0.001$ \\
\hline Primary or below & 7.4 & 5.2 & 9.4 & \\
\hline Secondary & 50.6 & 48.5 & 52.5 & \\
\hline University & 42 & 46.4 & 38.1 & \\
\hline Employment status, \% & & & & $<0.001$ \\
\hline Active & 34.2 & 38.2 & 30.4 & \\
\hline Unemployed & 7.2 & 5.7 & 8.7 & \\
\hline Retired & 42.0 & 47.6 & 36.9 & \\
\hline Family and home care & 7.6 & 0.7 & 13.9 & \\
\hline Pensioner & 9.0 & 7.8 & 10.1 & \\
\hline \multicolumn{5}{|l|}{ Chronic diseases } \\
\hline № (average) per individual (SD) & $3.5 \pm 2.5$ & $3.2 \pm 2.2$ & $3.8 \pm 2.7$ & $<0.001$ \\
\hline Bone, \% & 42.8 & 28.8 & 55.8 & $<0.001$ \\
\hline HPB, \% & 36.4 & 43.3 & 30 & $<0.001$ \\
\hline High cholesterol, \% & 34.3 & 31.9 & 36.5 & 0.042 \\
\hline Insomnia, \% & 25.7 & 18 & 32.7 & $<0.001$ \\
\hline Vision problems, \% & 21.7 & 18.4 & 24.8 & 0.001 \\
\hline \multicolumn{5}{|c|}{ Daily medication consumption, $\%$ ( $66.8 \%$ of the total), } \\
\hline 1-2 medications daily & 52.0 & 47.3 & 57.4 & 0.001 \\
\hline >3 medications daily & 48.0 & 52.7 & 42.6 & \\
\hline $\begin{array}{l}\text { Alcohol consumption* (last } \\
\text { year), } \%\end{array}$ & 78.3 & 84.6 & 72.5 & $<0.001$ \\
\hline
\end{tabular}


Tobacco consumption, \%

$<0.001$

Does not smoke daily

$\begin{array}{ccc}1.6 & 1.2 & 1.9 \\ 19.6 & 20.1 & 19.1 \\ 46.2 & 56.1 & 37.2 \\ 32.6 & 22.6 & 41.8\end{array}$

Social life, \% 0.024

Satisfactory (stays active)

52.0

51.0

54.0

Quiet (prefers to spend time

39.0

42.0

alone)

Hardly any social life, although

8.0

6.0

9.0

he/she would like one

Bad (lonely, with no one to turn to)

1.0

1.0

1.0

Sex life, \%

$<0.001$

Very good

4.5

5

4

Good

41

44 38

Normal 31

33 29

Bad

12 15

Very bad

6.5

6

0.02

Healthy lifestyle habits, \%

Exercises $\geq 3$ days/week

52.3

55.0

50.0

Exercises $\leq 1$ day/week,

27.0

27.0

27.0

Does not exercise (sedentary)

20.7

18.0

Eating habits, \%

Very good diet (Mediterranean

73.0

70.0

78.0

0.003

diet)

Diet could be improved

26.0

30.0

23.0

Unhealthy diet

1.0

1.0

1.0

1

${ }^{*}$ Consumption of any kind of alcoholic drink, even if only in exceptional circumstances

2

SD: Standard deviation; HBP: high blood pressure ** t-student, Mann-Whitney $U$ and Chi-squared tests

3

4

5

6 Table 2. State of health (clinical and psychological) as perceived by the sample 


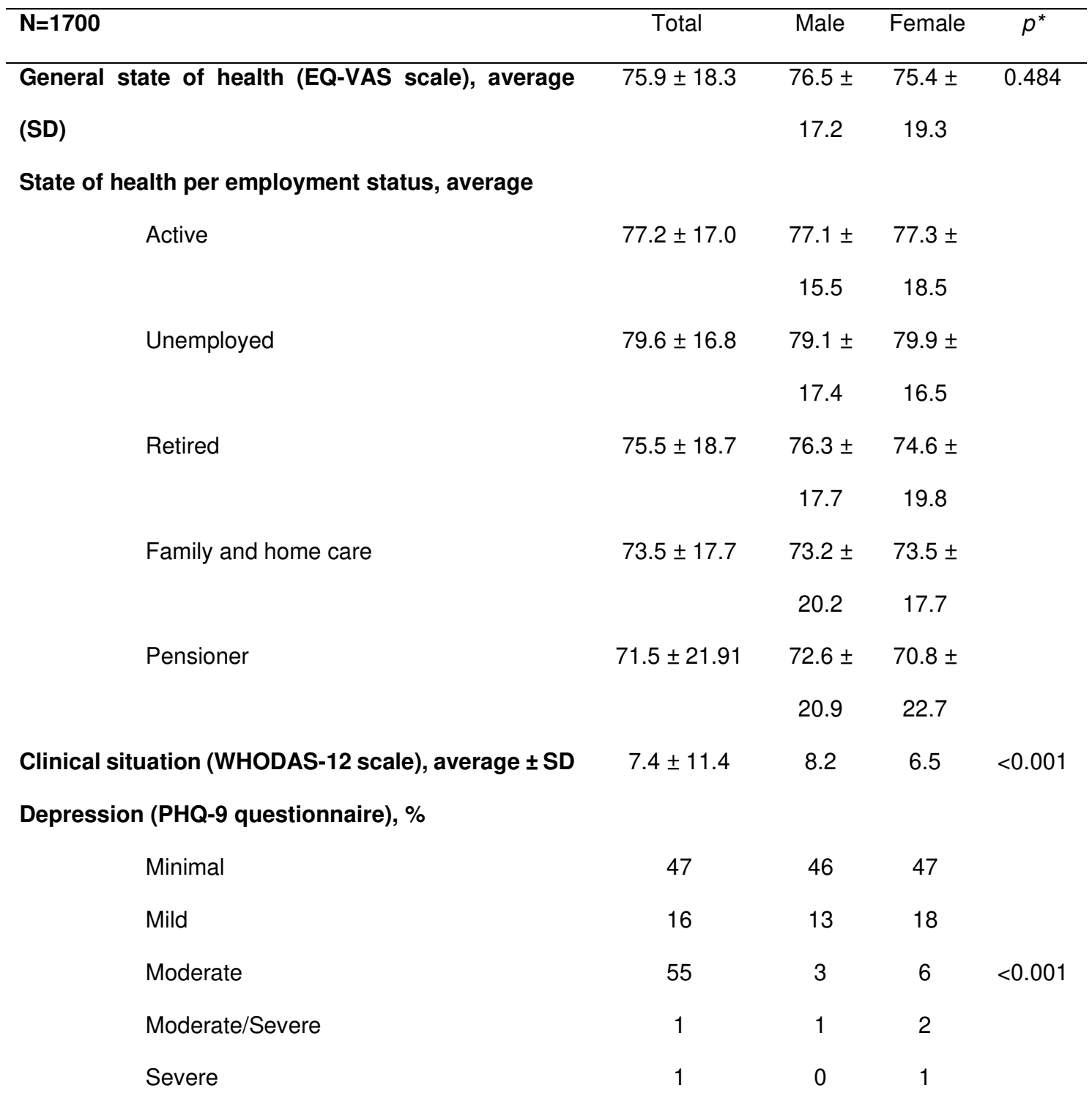

2 SD: Standard deviation; EQ-VAS= visual analogue scale to assess quality of life; WHODAS-12=

3 disability scale by the World Health Organisation; PHQ-9: Patient Health Questionnaire, 9 items.

4 * Mann-Whitney U, Kruskal Wallis and Chi-squared tests

5

6

7

10 Table 3: Linear regression model of self-perceived health status (EQ-VAS) by the 11 respondents $(n=1700)$, 


\begin{tabular}{|c|c|c|c|c|}
\hline \multirow{3}{*}{$\begin{array}{l}\text { Sociodemographic variables } \\
\end{array}$} & \multirow{2}{*}{$\begin{array}{c}\text { Model } \\
\text { Standardised } \beta \\
\text { coefficients }\end{array}$} & \multicolumn{3}{|c|}{ Model 2} \\
\hline & & $p$ & \multirow[t]{2}{*}{$\begin{array}{c}\text { Standardised } \beta \\
\text { coefficients }\end{array}$} & \multirow[t]{2}{*}{$p$} \\
\hline & & & & \\
\hline Gender & -0.033 & 0.111 & $-0.049^{*}$ & 0.017 \\
\hline Age & -0.033 & 0.132 & $-0.048^{*}$ & 0.025 \\
\hline Educational level & 0.007 & 0.728 & 0.006 & 0.778 \\
\hline Marital status & -0.037 & 0.068 & -0.033 & 0.096 \\
\hline Employment status & 0.000 & 0.993 & 0.003 & 0.903 \\
\hline \multicolumn{5}{|l|}{ Health variables } \\
\hline Disability: WHODAS-12 (0-100) & $-0.313^{*}$ & 0.000 & $-0.243^{*}$ & 0.000 \\
\hline № Chronic diseases & $-0.273^{\star}$ & 0.000 & $-0.214^{*}$ & 0.000 \\
\hline Sleep problems & $0.115^{\star}$ & 0.000 & $0.066^{\star}$ & 0.002 \\
\hline Smokes Yes/No & -0.021 & 0.290 & -0.022 & 0.275 \\
\hline PHQ-9 (0-27) & - & - & $-0.212^{*}$ & 0.000 \\
\hline Exercises $\geq 3$ days/week & $0.092^{*}$ & 0.000 & $0.083^{*}$ & 0.000 \\
\hline Healthy diet Yes/No & $0.067^{*}$ & 0.001 & $0.043^{*}$ & 0.036 \\
\hline Alcohol (wine or beer) Yes/No & $0.061^{*}$ & 0.003 & $0.056^{*}$ & 0.005 \\
\hline Adjusted $\mathrm{R}^{2}$ & 0.333 & & 0.363 & \\
\hline
\end{tabular}

2 Note: The table shows the standardised $\beta$ coefficients and significance levels: ${ }^{*} p<0.05$

3 WHODAS-12= disability scale by the World Health Organisation; EQ-VAS= visual analogue scale

4 to assess quality of life; PHQ-9: Patient Health Questionnaire, 9 items.

5 Linear regression model of self-perceived health status (EQ-VAS) by the respondents $(n=1700)$, taking into

6 account (model 2) or not (model 1) the level of depression according to the PHQ9 questionnaire. to employment status: active workers and retirees 


\begin{tabular}{|c|c|c|c|}
\hline $\mathrm{N}=1295$ & $\begin{array}{l}\text { Workers } \\
(n=581)\end{array}$ & $\begin{array}{l}\text { Retirees } \\
(n=714)\end{array}$ & $p^{* *}$ \\
\hline \multicolumn{4}{|l|}{ Gender } \\
\hline Male, \% & 53.7 & 54.3 & - \\
\hline Female, \% & 46.3 & 45.7 & - \\
\hline Age; years- average(SD) & $58.7 \pm 3.5$ & $67.5 \pm 3.9^{*}$ & $<0.001$ \\
\hline Married or in a couple, $\%$ & 77.5 & $73.5^{\star}$ & 0.003 \\
\hline \multicolumn{4}{|l|}{ Personal situation, \% } \\
\hline Lives alone & 8.8 & 17.6 & $<0.001$ \\
\hline Lives with partner and/or children & 77.8 & 74.3 & NS \\
\hline Lives alone with children and/or other family & 10.8 & 7.3 & NS \\
\hline Other & 2.6 & 0.0 & NS \\
\hline \multicolumn{4}{|l|}{ Educational level, \% } \\
\hline Primary or below & 2.7 & 9.5 & NS \\
\hline Secondary & 47.9 & 48.3 & NS \\
\hline University & 49.4 & $42.2^{*}$ & $<0.001$ \\
\hline \multicolumn{4}{|l|}{ Chronic diseases } \\
\hline № (average, SD) per individual & $3.1 \pm 2.4$ & $3.7 \pm 2.5^{\star}$ & $<0.001$ \\
\hline Bone, \% & 34.4 & $45.2^{*}$ & $<0.001$ \\
\hline HPB, \% & 30.3 & $42.8^{*}$ & 0.002 \\
\hline High cholesterol, \% & 34.1 & 34.3 & 0.929 \\
\hline Insomnia, \% & 23.6 & 25.1 & 0.535 \\
\hline Vision problems, \% & 16.8 & $24.4^{*}$ & 0.001 \\
\hline Sleep problems in the last month, $\%$ & 12.1 & 11.8 & - \\
\hline \multicolumn{4}{|c|}{ Daily medication consumption, $\%$ ( $72.8 \%$ of the total): } \\
\hline 1-2 medications daily, & 64.4 & 45.4 & NS \\
\hline 3-4 medications daily, & 25.4 & 35.6 & NS \\
\hline 5-6 medications daily, & 5.8 & 11.0 & NS \\
\hline$>6$ medications daily, & 4.4 & 8.0 & NS \\
\hline Alcohol consumption in the last year, $\%$ & 83.4 & $78.7^{*}$ & $<0.001$ \\
\hline
\end{tabular}




\begin{tabular}{|c|c|c|c|}
\hline Daily & 25.5 & $13.7^{*}$ & $<0.001$ \\
\hline Not daily & 3.4 & 0.5 & NS \\
\hline Ex-smoker & 43.5 & 52.3 & NS \\
\hline Non-smoker & 27.7 & 33.5 & NS \\
\hline \multicolumn{4}{|l|}{ Social life, \% } \\
\hline Satisfactory (stays active) & 50.1 & 57.1 & 0.049 \\
\hline Quiet (prefers to spend time alone) & 40.1 & 35.4 & - \\
\hline Hardly any social life, although he/she would like one & 8.3 & 6.7 & - \\
\hline Bad (lonely, with no one to turn to) & 1.5 & $0.8^{*}$ & 0.049 \\
\hline \multicolumn{4}{|l|}{ Sex life, \% } \\
\hline Very good / Good & $52.2 \%$ & $40.2 \% *$ & $<0.001$ \\
\hline Normal & $29.8 \%$ & $33.2 \%$ & - \\
\hline Bad / Very bad & $17.6 \%$ & $26.6 \%$ & - \\
\hline \multicolumn{4}{|l|}{ Healthy lifestyle habits, \% } \\
\hline Exercises $\geq 3$ days/week & 44.5 & $57.2^{*}$ & $<0.001$ \\
\hline Exercises $\leq 1$ day/week & 31.9 & 25.0 & - \\
\hline Does not exercise (sedentary & 23.6 & 17.8 & - \\
\hline \multicolumn{4}{|l|}{ Eating habits, $\%$} \\
\hline Very good diet (Mediterranean diet) & 68.3 & $76.6^{*}$ & 0.004 \\
\hline Diet could be improved & 30.6 & 22.6 & - \\
\hline Unhealthy diet & 1.0 & 0.8 & - \\
\hline
\end{tabular}

$1 \quad{ }^{\star}=$ statistically significant; ${ }^{\star \star}$ t-student, Mann-Whitney $U$ and chi-squared tests

2 NS = not significant, HBP: High blood pressure; WHODAS-12=edisability scale by the World

3 Health Organisation.

4

5

Table 5. Self-perceived health status (clinical and psychological) according to employment status: workers and retirees. 


\begin{tabular}{|c|c|c|c|}
\hline $\mathrm{N}=1295$ & $\begin{array}{l}\text { Workers } \\
(n=581)\end{array}$ & $\begin{array}{l}\text { Retirees } \\
(n=714)\end{array}$ & $P^{*}$ \\
\hline General state of health (EQ-VAS scale), average \pm SD & $77.2 \pm 17.0$ & $75.5 \pm 18.7$ & 0.389 \\
\hline Clinical situation (WHODAS-12 scale), average \pm SD & $6.89 \pm 11.4$ & $7.3 \pm 11.5$ & 0.662 \\
\hline Depression (PHQ-9 questionnaire), \% & & & 0.001 \\
\hline No & 26.5 & 36.5 & \\
\hline Minimal & 48.6 & 45.4 & \\
\hline Mild & 17.7 & 13.3 & \\
\hline Moderate & 5.6 & 2.9 & \\
\hline Moderate/Severe & 1.1 & 1.2 & \\
\hline Severe & 0.4 & 0.8 & \\
\hline
\end{tabular}

2 SD: Standard deviation; EQ-VAS= visual analogue scale to assess quality of life; WHODAS-12=

3 disability scale by the World Health Organisation; PHQ-9: Patient Health Questionnaire, 9 items.

4

* Mann-Whitney U and Chi-squared tests

5

6

7

8

9

10

11

12

13

14

15

18 Table 6: Linear regression model of perceived health status (EQ-VAS) for the sample according to employment status. 


\begin{tabular}{|c|c|c|c|}
\hline & \multicolumn{3}{|c|}{ Standardised $\beta$ coefficients } \\
\hline & Workers & Retirees & Total Sample \\
\hline \multicolumn{4}{|l|}{ Sociodemographic variables } \\
\hline Employment status & - & - & 0.018 \\
\hline Gender & $-0.098^{*}$ & -0.023 & $-0.054^{*}$ \\
\hline Age & -0.009 & -0.031 & -0.039 \\
\hline Educational level & 0.031 & -0.003 & 0.017 \\
\hline Marital status & -0.035 & -0.019 & -0.020 \\
\hline \multicolumn{4}{|l|}{ Health variables } \\
\hline Disability: WHODAS-12 (0-100) & $-0.191^{*}$ & $-0.259^{*}$ & $-0.238^{*}$ \\
\hline Depression PHQ9 (0-27) & $-0.307^{\star}$ & $-0.149^{*}$ & $-0.204^{*}$ \\
\hline Number of chronic diseases & $-0.181^{*}$ & $-0.240^{*}$ & $-0.221^{*}$ \\
\hline Sleeps well & 0.030 & $0.116^{*}$ & $0.084^{*}$ \\
\hline Smokes & -0.053 & 0.006 & -0.021 \\
\hline Exercises $\geq 3$ days/week & $0.102^{*}$ & 0.045 & $0.070^{*}$ \\
\hline Healthy diet & 0.001 & $0.088^{\star}$ & $0.051^{*}$ \\
\hline Alcohol (wine or beer with meals) & 0.038 & $0.095^{\star}$ & $0.073^{*}$ \\
\hline Adjusted $\mathrm{R}^{2}$ & 0.339 & 0.359 & 0.348 \\
\hline \multicolumn{4}{|l|}{${ }^{*} p<0.05$} \\
\hline
\end{tabular}

